\title{
Effective investment management with elements of simulation modelling
}

\author{
Lidia Shkurina ${ }^{1 *}$, Maria Maslova $^{1}$, Viktor Podsorin ${ }^{1}$, and Natalia Tereshina ${ }^{1}$ \\ ${ }^{1}$ Russian University of Transport, 127994, 9c9, Obraztsova st., Moscow, Russia
}

\begin{abstract}
Topical issues of investment management for the implementation of the Long-term Development Program of Russian Railways until 2025 are discussed in the article. It is proposed to use game simulation modelling for an investment plans' development in the context of limited investment resources.
\end{abstract}

\section{Updating tasks of investment management of infrastructure projects}

One cannot overestimate the importance of rail transport for the Russian economy. It is no doubt that the effective use of railways has an impact on economic growth of all economic entities using the services of an infrastructure company in the rail transportation field. JSC RZD is a network-wide public carrier of cargo, including for state needs. In addition, it is carried out terminal warehouse, transport and logistics activities. It is responsible for the maintenance, safety and cargo storage. We need a balanced policy for the infrastructure development and improvement of the technical condition parameters of infrastructure facilities to maintain a leading position in the transportation market. The load on the railway infrastructure has been increasing systemically in recent years, but the level of its development and technical equipment has not been improved significantly [1].

Despite the fact that the investments have significantly increased in development of railway transport (Fig.1), the amount is not sufficient to solve the problems faced by Russian Railways.

The projects aimed at the development of railway infrastructure and renewal of rolling stock (Fig. 2) are shown in Table 1.

\footnotetext{
${ }^{*}$ Corresponding author: efut2012@gmail.com
} 


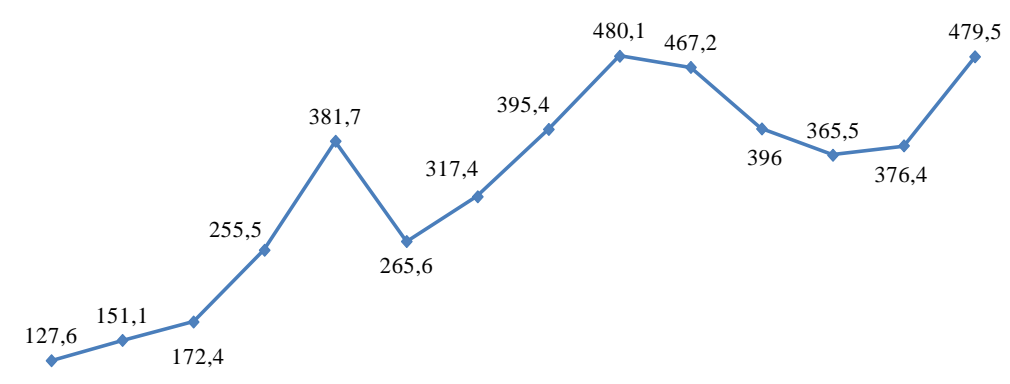

t

Fig. 1. The amount of the investment costs of JSC «Russian Railways» at the expense of all sources of financing, bln rub.

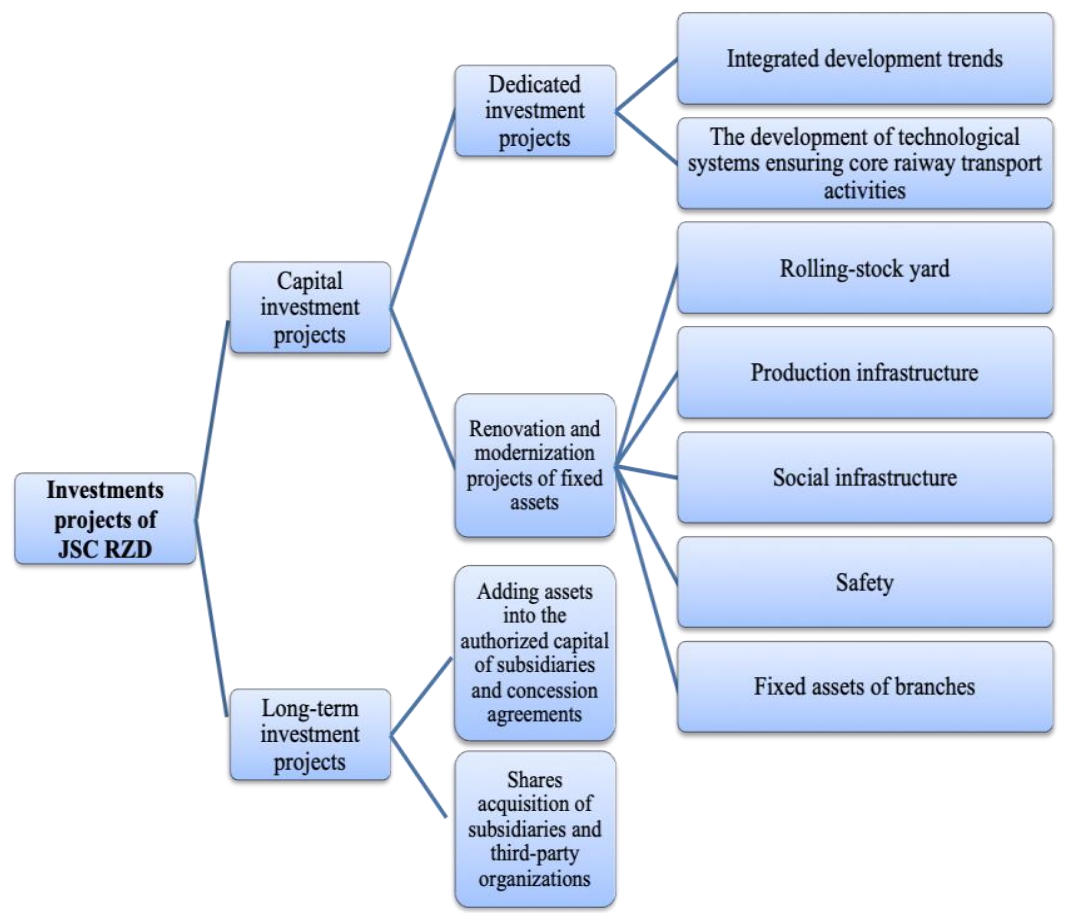

Fig. 2. The classification of investment projects of JSC «Russian Railways. 
Table 1. General performance's indicators of the Russian Railways' investment budget, bln rub.

\begin{tabular}{|c|c|c|c|c|c|c|c|}
\hline Sections & $\mathbf{2 0 1 1}$ & $\mathbf{2 0 1 2}$ & $\mathbf{2 0 1 3}$ & $\mathbf{2 0 1 4}$ & $\mathbf{2 0 1 5}$ & $\mathbf{2 0 1 6}$ & $\mathbf{2 0 1 7}$ \\
\hline 1 & 2 & 3 & 4 & 5 & 6 & 7 & 8 \\
\hline Total & 395,4 & 480,1 & 467,2 & 396 & 365,5 & 376,4 & 479,5 \\
\hline $\begin{array}{c}\text { Projects related to the } \\
\text { implementation of the } \\
\text { Russian Government } \\
\text { orders }\end{array}$ & 72,6 & 73,4 & 46 & 67,5 & 133,8 & 173,7 & 194,4 \\
\hline $\begin{array}{c}\text { Safety } \\
\text { constraints }\end{array}$ & 143 & 178,1 & 169 & 140,8 & 74,3 & 45,2 & 62,4 \\
\hline $\begin{array}{c}\text { Improving transport } \\
\text { accessibility for the } \\
\text { people }\end{array}$ & 18,8 & 36,4 & 59,5 & 12,8 & 13,2 & 12,2 & 15,6 \\
\hline $\begin{array}{c}\text { Removal of infrastructure } \\
\text { Renewal of rolling stock }\end{array}$ & 66,4 & 75,5 & 118,7 & 104,4 & 88,8 & 91,3 & 77 \\
\hline \begin{tabular}{c} 
Etc. \\
\hline
\end{tabular} & 19 & 49,8 & 17,9 & 23,6 & 11 & 12,2 & 15,3 \\
\hline
\end{tabular}

\section{The Long-Term Development Program for JSC RZD up to 2025}

\subsection{Investment priorities}

In the long-term development program of «Russian Railways» up to 2025 among the key challenges are noted:

- the need to reduce overdue overhaul kilometers track and locomotive fleet;

- the formation of sources for updating fixed assets;

- the decisions' implementation on the railway infrastructure development;

- the advancing infrastructure development for increasing volumes of freight and passenger traffic by providing services at a modern level of quality.

One of the main priorities of the program is the fulfillment of the targets of the comprehensive plan for the modernization and expansion of the backbone infrastructure as well as Presidential Decree on national objectives and strategic tasks of Russian Federation's development in the period up to 2024 dated May 07, 2018.

In the Long-term Development Program there are two versions of investing into the railway infrastructure' development: basic and optimistic. According to the base case the total investment is RUR 4671.4 billion over 2019-2024, and according to the optimistic one - RUR 5786.5 billion [2].

In order to ensure control over the targeted use of investment funds, a budgeting system is used. Budgeting provides to monitor the implementation of the investment program for each individual project and the program in general. 
When forming an investment program or more precisely planning its financing sources, the following principles should be observed:

- for projects with a payback period of 10-15 years the source of financing is own funds, as well as borrowed funds within the acceptable level of debt load;

- for projects with a payback period of 30 years funding is provided for using long-term financial instruments;

- for projects that have no economic effect for Russian Railways, financing should come from budgetary funds, as these projects have a multiplier effect for the country's economy.

To create conditions for balanced transport infrastructure's development and optimization of regional interaction between transport and economic entities (consumers of transport services) it is necessary to develop approaches that allow an effective investment management in case of limited financial resources and existing risks in the implementation of investment projects [3].

When forming the investment plan of the company, both corporate-wide projects and individual projects of functional branches are taken into account, due both to the condition of fixed assets and the prospects for technological development of each branch.

Thus, when developing an investment plan with limited investment resources, a game situation arises, which can be solved by simulation modelling methods.

To create an optimal investment plan and make a coordinated decision on financing a specific project, its importance and priority should be defined for the company and the branch. For these purposes, for each i-th project, the expected effect is calculated in the amount of E. In this case, the investment resources are distributed in proportion to the expected effects. If we denote the project priority coefficient as $\gamma$, then the project choice condition is $\gamma \mathrm{i}=\mathrm{Ei}$.

Each member of the investment plan (each branch) is interested in increasing the amount of allocated resources for finance investment projects.

The volume of investments allocated by the company to the branch for the implementation of investment projects can be taken as the objective function. In this case, a game situation arises. The game-theoretic simulation is used for its solving. Thus, when developing an optimal investment plan, the following conditions have to be made:

$$
\begin{gathered}
R \geq \sum_{i=1}^{K} x_{i}+y_{i} \cdot \sum_{i=K+1}^{n} \gamma_{i} \\
R<\sum_{i=1}^{K} x_{i}+\sum_{i=K+2}^{n} y_{K+1} \cdot \sum \gamma_{1}
\end{gathered}
$$

$\mathrm{R}$ - total planned investment resources;

$\mathrm{xi}$ - the volume of investments declared for financing by a specific branch for the $\mathrm{i}$-th project;

yi - coefficient reflecting the project's priority.

The volume of investments for each branch is determined by the formula:

$$
y=\frac{R-\sum_{i=1}^{K} x_{i}}{\sum_{i=K}^{n} \gamma_{i}}
$$

The distribution of investment resources for projects of branches is made until an equilibrium plan is drawn up [4]. 
It should be noted that in this research has been considered the option of allocating resources to branches and projects with long-term and medium-term planning for all projects at the same time. But along with this option, other approaches can be used.

For instance, the option with reverse priorities, the less investment resources are required for a project, the higher the priority coefficient is, as well as the option with a competitive allocation of resources.

With competitive distribution, the problem of balanced and balanced development of the company is solved. The effect obtained from the implementation of projects is max in the corporate system.

\subsection{A formation of functional model for investment management}

Developing and implementing this investment resource allocation model, it is necessary to develop a system of clusters' factors. They characterize the state of the external environment in which this branch operates, as well as the state of the internal environment, the state of fixed assets and the level of technical and technological development, the availability of investment resources in past periods [5].

Thus, the functional model of the investment management system includes the principles and methods of management in active systems built on the principles of gametheoretic simulation. It can be implemented in several stages (Fig. 3).

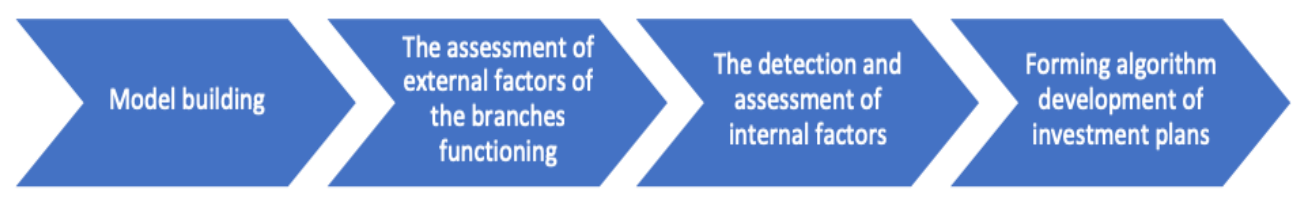

Fig. 3. Stages of developing an optimal plan

The optimally developed system of forming an investment plan in the context of limited financial resources ensures the economic viability of investment activities.

Conclusions and recommendations based on the results of the study

1. The effective operation of Railways affects the economic growth of all economic entities that use the services of the infrastructure company in the industry of rail transport

2. To create conditions for a balanced development of transport infrastructure and optimize regional interaction between transport and economic entities (consumers of transport services), it is necessary to develop approaches to effectively manage investments in the event of limited financial resources and existing risks in the implementation of investments.

3. The functional model of the investment management system includes the principles and methods of managing active systems, built on the principles of game-theoretic simulation. The optimally developed system of forming an investment plan in conditions of limited financial resources ensures the economic viability of investment activities [6].

\section{References}

1. L.V. Shkurina V.A. Bilokha, I.V. Tokareva, The corporate governance system in investment activity in the railway transport: concept and methodology (2010) 
2. L.V. Shkurina, S.A. Maskaev, The concept and methodology of managing the property potential of railway transport in the organization of cargo transportation in international traffic (2015)

3. L.V. Shkurina, Yu.A. Khareva, Manag. Comper. R.way. Infr. Co. (2018)

4. N.P. Tereshina, V.A. Podsorin; Ed. N. P. Tereshina, Management of Innovations in Railway Transport, 592 (2012)

5. V.A. Podsorin, Transp., Sci., Tech. manag.. Sci. Inf. Coll., 6 (2007)

6. N.P. Tereshina, Economic Regulation and Transportation Competitiveness (1994) 